\title{
Naturismo Ulwa en Karawala
}

\section{Leonzo Knight}

Este artículo es el anticipo de un libro en proceso de publicación el cual es producto de un programa de investigación in situ desarrollado con ancianos/as ulwas de la antigua comunidad de Awawak, hoy llamada Karawala. Es un esfuerzo de transmisión de conocimientos de nuestra cultura ancestral, lo cual se viene haciendo desde que se conformó, en 1988, la organización de rescate cultural ulwa CODIUL/UYUTMUBAL. Estas investigaciones han sido posibles gracias al trabajo voluntario realizado por el autor de este libro, con el apoyo de los hermanos norteamericanos Dr. Ken Hale (q.e p.d.) y Dr. Tom Green; y con la participación de hermanos comunitarios como Manuel Simon Walter, Jonahtan Julian, Mandro Julian, Ernesto Rafael y Elona su esposa, Levai Simon, Bina Briton, Silviston Wallen, Justina Patterson, Amalia, Raquel Martinez, Genora Ellick, Tomàs Gamboa, Justecia Blanco, Irma Blanco, Cecilia Palmiston, Gregoria Palmiston, Osefa Wallen, Reyna Simón, Martin Crimins, Francklin Crimins, Narciso Simon, Prudencia Francis, que ya han fallecido, y los actuales portadores culturales que aparecen en el texto.

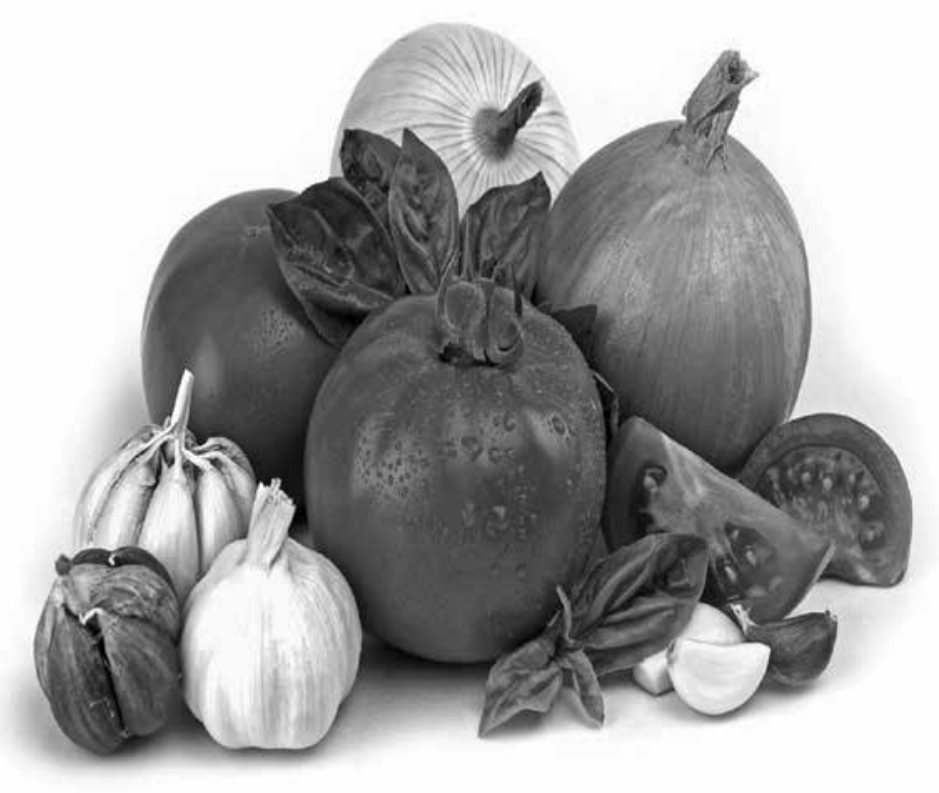

\begin{tabular}{|l|l|l|}
\hline \multicolumn{1}{|c|}{ Enfermedad } & \multicolumn{1}{|c|}{ Receta } & Portador cultural \\
\hline $\begin{array}{l}\text { Cómo dejar de } \\
\text { fumar }\end{array}$ & $\begin{array}{l}\text { Obtener el centro del tallo de un árbol de pino; luego mezclar parte de } \\
\text { este material con tabaco y fumarlo en ayunas. Repetir esta operación por } \\
\text { cinco días (no ingerir bebidas alcohólicas ni gaseosas. Evítese el uso de } \\
\text { pimienta, mostaza, vinagre y café). }\end{array}$ & Morfy Salazar \\
\hline Parasitosis & $\begin{array}{l}\text { Machacar semillas de papaya en una taza, luego ingerirlas dos veces al } \\
\text { día, en ayunas y al acostarse. Repetir la dosis por tres días solamente. }\end{array}$ & Juan Taylor \\
\hline Presión baja & $\begin{array}{l}\text { 1. } \\
\text { La semilla de aguacate partirla en cruz y hervirla en un litro de agua. } \\
\text { Tomar tres vasos diarios por más de un mes. }\end{array}$ & Morfy Salazar \\
\hline Presión alta & $\begin{array}{l}\text { 2. } \begin{array}{l}\text { Ingerir un diente de ajo en jugo de naranja o limón. Tomarlo en ayunas } \\
\text { por un tiempo determinado. }\end{array} \\
\text { 1. } \begin{array}{l}\text { Dejar reposar la semilla de tamarindo maduro en un recipiente con un litro } \\
\text { de agua, por un espacio de veinte minutos, y luego tomar cada cinco horas. } \\
\text { Machacar un diente de ajo, luego dejarlo reposar en jugo de naranja o de } \\
\text { tamarindo. Tomarlo en ayunas y al acostarse. Hacer esto por más de un } \\
\text { mes, para curarse definitivamente. }\end{array}\end{array}$ & Morfy Salazar \\
\hline
\end{tabular}




\begin{tabular}{|c|c|c|}
\hline Bocio & $\begin{array}{l}\text { Recoger cinco hojas de una flor llamada campana. Cuatro de estas hojas } \\
\text { envolverlas en una tela y machacarlas muy bien. Después sacarlas del trapo, } \\
\text { y en la hoja sobrante que no se ha utilizado mezclarlas con un poco de zepol } \\
\text { y aplicarlas sobre el bocio. Hacer esto diariamente hasta que la enfermedad } \\
\text { se cure. }\end{array}$ & Carmela Baptis \\
\hline Infección renal & $\begin{array}{l}\text { 1. Recoger tres trozos del tallo de mango y hervir en un litro de agua. Tomarlo } \\
\text { tres veces diariamente por tres días. } \\
\text { 2. Hervir hoja de almendro de playa junto con culantro en unos tres litros } \\
\text { de agua. Tomarlo por un mes. }\end{array}$ & $\begin{array}{l}\text { Glenford William } \\
\text { Betsy Logan }\end{array}$ \\
\hline $\begin{array}{l}\text { Hemorragias } \\
\text { vaginales }\end{array}$ & $\begin{array}{l}\text { Hervir una semilla de aguacate picado en un litro de agua y tomar una parte. } \\
\text { Hacer lavado vaginal con la parte sobrante. }\end{array}$ & Lever Gamboa \\
\hline Flor blanca & $\begin{array}{l}\text { Recoger raíces de garrapata y de pisabet, y con las branquias del pez mojarra } \\
\text { echarlas en una botella y tapar muy bien. Luego ponerlas a hervir en una porra. } \\
\text { En este punto verter el contenido de la botella en el recipiente y dejarlo hervir } \\
\text { por sesenta minutos. Luego sacarlo y, cuando se enfrié, tomarlo por siete días. }\end{array}$ & Gloria Knight \\
\hline Desnutrición & $\begin{array}{l}\text { Cortar en forma de cruz la semilla de guacal ( } \mathrm{kahmi} \text { ). Dentro de la semilla } \\
\text { encontrará unos residuos blancos los cuales mezclará con azúcar y los pondrá } \\
\text { a cocer. Durante su cocción agregará culantro, canela y albahaca. Al término } \\
\text { de la cocción echará } 12 \text { pastillas de sulfatiazol, dos esencias y un litro de vino. }\end{array}$ & Clemencia William \\
\hline Tos & $\begin{array}{l}\text { Picar bien una cebolla, mezclar con miel de abeja y dejarla reposar por } \\
\text { veinticuatro horas. Luego agregar jugo de limón castillo. Tomar una cucharada } \\
\text { cada tres horas. }\end{array}$ & Lever Gamboa \\
\hline Alergias de la piel & $\begin{array}{l}\text { Hervir una libra de corteza de mango en cuatro tazas de agua. Luego lavar } \\
\text { con esto la piel tres veces al día. }\end{array}$ & Lever Gamboa \\
\hline Diarreas & $\begin{array}{l}\text { 1. Mezclar tres cucharadas de almidón de yuca con el jugo de limón y tomar } \\
\text { una vez al día. } \\
\text { 2. Cocer la cáscara de banano verde y tomar tres veces al día. }\end{array}$ & Lever Gamboa \\
\hline Anemia & $\begin{array}{l}\text { 1. Hervir con leche raíz de cuculmeca y endulzar con miel de abeja. Tomarla } \\
\text { tres veces diariamente por siete días. } \\
\text { 2. Tomar jugo de remolacha y de zanahoria mezcladas con vino. } \\
\text { 3. Licuar una piña madura con jugo de diez naranjas y media libra de hígado } \\
\text { crudo y tomarlo. Hacer esto por quince días. }\end{array}$ & Lever Gamboa \\
\hline Asma & $\begin{array}{l}\text { 1. Hervir una taza de leche. En este punto agregar dos dientes de ajo y dejar } \\
\text { reposar. Tomarlo luego por la noche. } \\
\text { 2. Machacar hojas de llantén, endulzar con miel de abejas y tomarlo. }\end{array}$ & Lever Gamboa \\
\hline Empacho & En una taza de agua hervir apio, hoja de menta o hierba buena y tomarlo. & Lever Gamboa \\
\hline Ulceras & Licuar el tronco del repollo y tomar el jugo antes de cada comida. & Lever Gamboa \\
\hline
\end{tabular}




\begin{tabular}{|c|c|c|}
\hline $\begin{array}{l}\text { Afecciones } \\
\text { vaginales }\end{array}$ & $\begin{array}{l}\text { Mezclar, en un litro de agua, dos cucharadas de sal, una de vinagre y el jugo } \\
\text { de dos limones. Hacer lavados vaginales con esta mezcla. }\end{array}$ & Lever Gamboa \\
\hline Próstata & $\begin{array}{l}\text { Conseguir } 21 \text { hojas de cada una de estas variedades de plantas: pisik, carau, } \\
\text { tisling y almendro. Después hervirlas todas en un litro y medio de agua } \\
\text { por } 10 \text { minutos y tomarlo luego ya frío. Posteriormente, a los residuos que } \\
\text { quedan sedimentados echarles otros dos litros de agua y luego tomarlo. } \\
\text { Después, a los residuos que quedan sedimentados echarles otros dos litros de } \\
\text { agua, agitarlos muy bien y lavar con esto la parte del cuerpo en donde está } \\
\text { ubicada la próstata. Finalmente, con el último residuo que queda después } \\
\text { de lavar mezclarlo con brillantina y hacerse masajes en la parte donde se } \\
\text { ubica la próstata. }\end{array}$ & Gloria Night \\
\hline $\begin{array}{l}\text { Dolores intensos } \\
\text { en el intestino } \\
(\text { yumo })\end{array}$ & $\begin{array}{l}\text { Conseguir raíz de } k r u \text {, de prak praky de belta. Luego cocerlas y, posteriormente } \\
\text { tomar por } 15 \text { días. }\end{array}$ & Teófilo Miller \\
\hline Vómito & Cocer un limón castillo en un litro de agua y luego tomar un vaso. & Leonardo Simón \\
\hline Reumatismo & $\begin{array}{l}\text { Obtener semilla de almendro de bosque y freírla en un poco de aceite; rayar } \\
\text { tres libras de gengibre y mezclarlas con la manteca que se obtuvo de la semilla } \\
\text { de almendra. Luego aplicar el producto con masajes en las partes donde duele. }\end{array}$ & $\begin{array}{l}\text { Liliam Crimins } \\
\text { Francis }\end{array}$ \\
\hline Colitis vaginales & $\begin{array}{l}\text { Dos raíces de pisabet, tres hojas de escoba lisa y hervir en leche. Tomar un } \\
\text { litro diaria por } 7 \text { días. }\end{array}$ & Guillermina Miller \\
\hline $\begin{array}{l}\text { Afecciones } \\
\text { renales }\end{array}$ & $\begin{array}{l}\text { Siete hojas de lula bakbak, hervirlas en un litro de água, y tomar como agua } \\
\text { hasta sanar. }\end{array}$ & Teófilo Miller \\
\hline Anemia & $\begin{array}{l}\text { Obtener lahwa taya, indio pelado y raíz de cuculmeca; hervirlo todo en cuatro } \\
\text { litros de agua; después agregar un litro de vino, esencia y tomarlo luego. }\end{array}$ & Irene Miller \\
\hline Parásitos de leche & $\begin{array}{l}\text { Pelar el palo de kuah y recoger, en un recipiente, la leche que segrega esta } \\
\text { acción. Tomar tres cucharadas de esta leche y mezclarla en medio vaso de } \\
\text { leche; después tomar una sola dosis. }\end{array}$ & Irene Miller \\
\hline Lepra de Montaña & $\begin{array}{l}\text { Obtener hojas de hierba llamada urus bamba, envolverla en un trozo de tela } \\
\text { bien limpia y picarla muy bien. Del líquido que segrega esta acción aplicar } \\
\text { unas gotitas en la parte afectada. En la mañana se cuece la cáscara de kâwi } \\
\text { y se lava con la misma cocción. Este procedimento se repite hasta curar la } \\
\text { enfermedad. }\end{array}$ & Juan Salazar \\
\hline Mabita o Kuaihka & Hervir raíces y hojas de dormilona e ispriri en un litro de agua y luego tomar. & Silvia Miller \\
\hline $\begin{array}{l}\text { Para salir } \\
\text { embarazada }\end{array}$ & Mezclar las hojas de nikru tawa bien picadas en un litro de agua y tomarlo. & Silvia Miller \\
\hline
\end{tabular}

